\title{
Preparing staff for problem-based learning: Outcomes of a comprehensive faculty development program
}

Lim, Lisa-Angelique Yuen Lie $\searrow>$
Republic Polytechnic, Singapore (lisaalim@gmail.com)

Choy, Lyn Fung Jeanette

Republic Polytechnic, Singapore(jeanette_choy@rp.edu.sg)

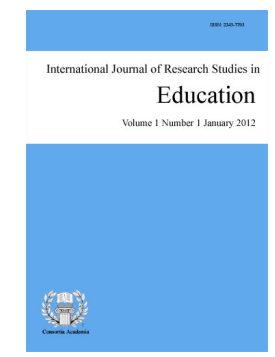

ISSN: 2243-7703 Online ISSN: 2243-7711

Received: 29 May 2014

Revised: 29 June 2014 DOI: 10.5861 /ijrse.2014.821

Accepted: 6 July 2014

OPEN ACCESS

\section{Abstract}

This study reports an investigation into the impact of a structured foundational staff development program on new academics in their role as classroom tutors in a problem-based learning (PBL) environment. The program aims to provide a systematic framework to share knowledge, skills and attitudes necessary for new academics to be competent and confident tutors who can provide valued and valuable learning experiences for students' learning in a PBL environment. To measure the outcomes of this program, Kirkpatrick's (1994) framework was adopted, and outcomes were evaluated according to reaction, learning, and behavior. Quantitative data were collected in the form of student feedback scores, tutor confidence, and attitudes toward teaching, while a post-program survey was used to collect qualitative data. The results indicate that the program had brought about gains in knowledge regarding principles and/or strategies of self-directed learning, as well as a detectable change in academics' orientation towards teaching and learning to a more developmental perspective. Moreover, participants noted that they were able to apply their learning in terms of promoting key student behaviors in PBL, such as collaborative learning. The evaluation suggests that, for the successful implementation of PBL, it is important for a structured foundational training program to address not only the essential elements of PBL, but also the role of the tutor, especially in terms of addressing the teaching beliefs of staff, and helping them to adapt to the constructivist belief system embedded in the PBL environment.

Keywords: faculty development; problem-based learning; teaching perspective; evaluation; higher education 


\section{Preparing staff for problem-based learning: Outcomes of a comprehensive faculty development program}

\section{Introduction}

Educators who are new to problem-based learning (PBL) are faced with a qualitatively different teaching pedagogy which may be at odds with their own accustomed practices. As PBL is a constructivist, learner-centered approach, the role of the PBL tutor is facilitative rather than directive-instead of transmitting information to students, the goals of the tutor are to facilitate discussions in the classroom in order to allow for the social construction of knowledge, and to help students become more independent learners (Hmelo-Silver \& Barrows, 2006). In the attempt to scaffold student learning, the challenge is for tutors to hold back the tendency to act as content resource for students; in this sense, the act of supporting students in PBL requires 'sophisticated facilitation skills' (Papinczak, 2010). Similarly, the idea of giving up control in such a learner-centered environment can be hard to accept, especially for teaching staff who are more used to making decisions regarding student learning in their classrooms (Lekalakala-Mokgele, 2010). Finally, in addition to a new role, new PBL tutors face the added challenge of having to teach in a multidisciplinary context, instead of within the confines of their own subject area; this raises concerns of being able to cover the required syllabus in the given time (Farmer, 2004).

The challenges outlined above bear implications for faculty development. Foremost, it is argued that in fact the success of PBL hinges on the effectiveness of teaching staff, and therefore, the training of tutors in preparation to teach through this pedagogy is essential. In fact, the meta-analysis by Leary and her colleagues suggest that without training, student learning gains are equivalent to those under lecture-based teaching (Leary, Walker, Shelton, \& Fitt, 2013). Without adequate training, Hung (2011) also suggests a possibility that staff will revert to more transmissive or lecture modes of teaching. As to what constitutes adequate training, there is a suggestion that there is a need for a well-structured, comprehensive training program rather than piecemeal one-off workshops (Farmer, 2004; Murray \& Savin-Baden, 2000). This is because a continuous training roadmap provides ongoing support to teaching staff in their journey as facilitators of student learning in PBL. This ongoing professional development also provides opportunities for staff to explore new skills as well as to reflect on their classroom practice (Kolmos, Du, Dahms, \& Qvist, 2008). In planning for staff development for PBL, Irby (1996) highlights specifically that such a program should achieve three outcomes: 1) help new staff understand the rationale for the pedagogy; 2) stimulate staff to challenge their conceptions about learning; and 3) facilitate the development of specific facilitation skills for the classroom.

The past two decades have seen a proliferation of PBL in higher education, from medical education to a diversity of other professional disciplines such as architecture, law, social work, and teacher education (Hung, Jonassen, \& Liu, 2008), and accordingly, research on the implementation and outcomes of these. However, comparatively lesser research is available on the faculty development initiatives that accompany the implementation of PBL, and more importantly, evaluations of these initiatives. To the extent that the effective implementation of PBL is contingent on the effectiveness of teaching staff, evaluating the outcomes of faculty development for PBL presents a significant research gap (Leary et al., 2013), which the present study aims to fill. The following section reviews some of the research on faculty development for PBL and its outcomes, as well as reviews on the evaluation of faculty development.

\subsection{Faculty development for problem-based learning}

A number of works have been published to describe faculty development programs for PBL, especially in the health professions. Such programs can range from an introductory day session to extended programs involving a series of training workshops over a period of time. Most of these programs appear to address Irby's 
Preparing staff for problem-based learning: Outcomes of a comprehensive faculty development program

(1996) recommendations of helping staff understand the rationale for the pedagogy. For example, Murray \& Savin-Baden (2000) describe how the introductory session for new PBL tutors in a nursing program builds in time for a discussion of the research and principles underlying PBL. Other programs appear to focus more on the development of specific skills for implementing PBL. For example, Dalrymple and her colleagues (Dalrymple et al., 2007; Dalrymple, Wuenschell, \& Shuler, 2006; Wuenschell, Dalrymple, \& Shuler, 2007) describe a program for dental educators, focusing on core skills needed in PBL in areas such as facilitation of student learning, and conduct of assessment.

In many cases, faculty development programs for PBL include opportunities for new staff to experience problem-based learning, either through observations (Baroffio, Kayser, Vermeulen, Jacquet, \& Vu, 1999; Evans \& Taylor, 1996) or simulations and role-plays (Dalrymple et al., 2006; Kolmos et al., 2008; Murray \& Savin-Baden, 2000). This component of personal experience with PBL is important in order to help new staff examine their own teaching conceptions in light of this pedagogy (Irby, 1996) and even to embrace it (Farmer, 2004).

\subsection{Measuring the outcomes of faculty development programs}

Given the amount of time and resources invested in implementing faculty development programs, and also that it is frequently a requirement for staff to attend such programs, it is important to document the outcomes of the program to justify that investment (Guskey, 2002). Some researchers (Desimone, 2009; Stes, Coertjens, \& Petegem, 2010) have argued critically that program evaluations of faculty development, though important, have tended to focus on measuring participants' satisfaction alone, when there needs to be closer attention to its results or to understanding the processes which make it effective or not. This could be evidenced by Steinert et al.'s (2006) earlier review of 53 faculty development programs in medical education from 1980 to 2002, whereby they found that $74 \%$ of these works assessed participant reactions. At the same time however, the reviewers noted that other types of outcomes were also assessed-77\% of evaluations assessed participants' learning, and $72 \%$ assessed behavior change. Notably fewer studies assessed impact at higher levels, such as change in organisational practice or change in student and resident learning (13\% and $6 \%$ respectively).

More recently, the emphasis on participant reaction or satisfaction still seems apparent (Dalrymple et al., 2007; Kolmos et al., 2008). However, evaluations of faculty development programs have begun to explore other outcomes. Boerboom et al.'s (2009) evaluation of a faculty development program for student-centered learning in veterinary medicine, for example, measured the extent to which teachers' perceived competence in seven different teacher roles improved as a result of the program, the extent to which experience mediated the change. Comparing staff who completed the program with those who did not, they found that participants who had completed the program emerged with perceived higher competence in their roles as teacher, content expert, and scholar. The years of teaching experience also mediated the effects of participants' role-perceptions. Other evaluations have explored student feedback as a way to understand the impact of faculty development. In her studies, Anne Baroffio and her colleagues measured student feedback to investigate different questions-firstly, to find out whether the training program improved PBL tutors' skills (Baroffio et al., 1999); and secondly, to find out the extent to which workshop effectiveness was affected by prior performance of tutors and their teaching context (Baroffio et al., 2006). Her findings provided evidence that participation in faculty development for PBL improved some but not all facilitation skills, and that programs which are designed to address participants' specific needs was effective in helping to develop and improve teaching skills. Overall, investigations into different types of outcomes as a result of faculty development have not only been helpful in measuring the impact of such programs, but are also helpful in understanding the implications for effective programs.

\subsection{Purpose of the study}

Other than the meta-review by Leary et al (2013), lesser research has been conducted on faculty development programs for PBL in a multi-disciplinary setting, not just within a certain teaching context like 
Lim, L.-A. Y. L. \& Choy, L. F. J.

medical education or engineering. What could such a program look like? Furthermore, what would be the impact of such a program on new PBL tutors in this setting? What are some components of the program which make it effective for the audience? To the best of our knowledge, there has been little documentation on the development and support of tutors for PBL, and even fewer studies on the outcomes of such programs. Hence, the purposes of this study are to describe a faculty development program for PBL that cuts across all disciplines, and to investigate outcomes beyond participant satisfaction.

\subsection{Research Questions}

In order to examine the outcomes of the program more rigorously, Kirkpatrick's four-level model of training evaluation and criteria (Kirkpatrick, 1994) was adopted as the framework for the evaluation of the PBL Foundation program. Listed below are the specific sub-questions that are generated based on the Kirkpatrick's model.

1. What are staff's reactions (satisfaction) to the program? (Level 1 - Reaction)

2. What effect did the program have on staff's knowledge, attitudes, and beliefs? (Level 2 - Learning)

3. What effect did the program have on staff's classroom practices? (Level 3 - Behavior)

Level 4 of Kirkpatrick's model of evaluation examines impact of programs on results. In an education setting, results refer to students' academic performance. The present study did not explore program outcomes at this level, as the design did not allow for an appropriate baseline comparison. Furthermore, research has found it challenging to link any improvement in student performance outcomes directly to programs, because of other variables which may influence these results as well (Desimone, 2009). These variables may include student factors as well as experiences outside of formal training workshops which contribute to teacher learning. Thus the focus of this investigation is to examine the outcomes at the first three levels, and to be able to link these directly to the program, in order to more fully understand its impact.

Finally, this research also explored the following question: What other internal/external factors impact the effectiveness of the program?

\subsection{Context of the study}

The study was conducted at a post-secondary educational institution which implements PBL as the main pedagogical approach for all its diploma programs.

At this institution, the faculty development program for new staff is referred to as the PBL Foundation program. The program comprises a series of workshops and lesson observation sessions experienced over a maximum of eighteen months, making up a total of 104 training hours. This comprehensive program attempts to communicate the essential principles of PBL through a platform that is open to critical scrutiny and capable of effective translation into practice through facilitated discussions and reflective practice. All new academic staff are required to attend a 40-hour PBL Introduction workshop before they can start facilitating students in the classroom. Over the next 18 months, besides taking on classes and performing other department-related duties, staff are expected to attend seven individual workshops, addressing specific facilitation skills, classroom management, and assessing students learning in PBL. In addition, they are also required to observe at least one lesson by a peer coach with pre and post observation discussions, and be observed by a peer coach with pre- and post- observation discussions. Table 1 presents an overview of the program. 
Preparing staff for problem-based learning: Outcomes of a comprehensive faculty development program

Table 1

The PBL Foundation Program for new staff

\begin{tabular}{ll}
\hline Categories & Workshop Title \\
\hline Induction & PBL Introduction \\
On-the-job & Observation of a peer coach's class \\
& Being observed in class by a peer coach with discussions \\
Formal & Holistic assessment \\
classroom-based & Encouraging meaningful reflection \\
workshops & Understanding youth behavior \& learning \\
& Motivating learners to be self-directed \\
& Managing the PBL classroom \\
& Listening \& questioning \\
& Strategies to facilitate collaborative learning among students \\
\hline
\end{tabular}

The structured PBL Foundation program was introduced to provide staff with more systematic support in line with the institution's on-going commitment to provide a valued and valuable learning experience for students. The PBL Introduction workshop is offered as frequently as ten times in a year, so as to accommodate new staff who join the institution at different points. Although there are other program offerings, this particular foundation program focuses on the component of instructional development. As such, it is a general skills model, similar to that of McMaster, which "focuses on a general model of PBL and on generic tutor training" (Irby, 1996, p. 76).

The expected outcomes of this program are based on the knowledge, skills, competencies and attitudes required of a tutor in a PBL environment. Specifically, upon completion of the PBL Foundation program, tutors are expected to be able to:

1. Articulate and incorporate key student learning behaviors: collaboration, self-direction and reflection in his/her facilitation,

2. Understand and respond appropriately to students according to their needs,

3. Assess students holistically based not just on their conceptual understanding but also on their learning process and progress as learners,

4. Engage in meaningful reflection for professional development.

\section{Method}

\subsection{Participants}

Participants in this study were selected based on the following criteria: they had to be new full-time staff from different departments who attended the PBL Introduction training in the months of April 2009 to April 2011, and who had completed the entire 104-hour program by the end of June 2012. A total of 309 full-time and adjunct staff attended the introductory program over the period of data collection; however, this study only included full-time teaching staff. By the end of the data collection period, 95 full-time staff had completed the program. The median time taken by these staff to complete the entire program was 15 months. Surveys were administered to these staff as and when they had completed the program. The final sample consisted of 39 participants (49\% female) with $67 \%$ having facilitated not more than 3 semesters of PBL classes by the time they completed the program.

\subsection{Data and instruments}

As noted earlier, the framework guiding this study was Kirkpatrick's (1994) model of training evaluation, 
thereby providing multiple indicators to explore the impact of the program. To answer the research questions, both quantitative and qualitative data were collected, in a concurrent mixed methods design (Clark \& Creswell, 2011). In this design, integration of data sources occurred at the point of data collection, as qualitative open-ended questions were added in the quantitative survey. As such, qualitative data were complementary to the quantitative data, and helped to explain the results. The main source of qualitative data was a survey which asked participants to provide written input about their satisfaction with the various components of the program, their confidence in facilitation, the key ideas that they had taken away, some ideas they had implemented in their facilitation as a result of the program, and any barriers to their implementation.

The written survey also requested participants to record their Teaching Perspective Inventory, TPI (Pratt \& Collins, 2001) scores at the time when they first joined the institution and at the end of the PBL Foundation training program. The TPI, which is a measure of an individual's orientation to teaching, generates five alternative points of view (perspectives) on teaching by asking structured questions about what teachers do in the teaching setting, their intentions behind their actions, and their beliefs about fundamental principles of teaching and learning. These five different views are: 1) Transmission, 2) Apprenticeship, 3) Developmental, 4) Nurturing, and 5) Social Reform (see Pratt and Collins, 2001, for a full description of these perspectives). These views are orthogonal—an individual can hold any or all these views together, to differing degrees. The instrument helps to identify the individual's 'dominant', 'recessive', and 'backup' perspectives, based on the standard deviations around the means of each perspective. The TPI consists of 45 items requiring a response on a 5-point likert-scale. To date, the authors have captured approximately 100,000 respondents from educators all over the world by putting the instrument online; based on this huge sample base, Collins and Pratt (2011) found satisfactory reliability of .75 across all five scales. In the PBL Foundation program, participants are asked to complete the TPI online prior to the commencement of the workshop, and to keep a printout of their results for reflection and discussion; they are also encouraged to take the TPI again at different points of their teaching career in order to keep reflecting on their teaching orientations.

In addition, data were also collected on participants' student feedback scores. Administered at around the $10^{\text {th }}$ week of every semester, the student feedback survey is a formative tool to provide facilitators with feedback about their facilitation based on the students' perspectives. This validated instrument was based on research in, and developed specifically for, PBL settings, designed to measure perceived tutor behaviors in PBL (Schmidt \& Moust, 1995). There are a total of 10 items in the facilitator section measuring three different tutor characteristics, namely: (i) Social congruence (4 items), (ii) Use of subject-matter expertise ( 2 items) and (iii) Cognitive congruence (4 items). These data were collected at two points: Stage 1-in staff's first semester of teaching after the PBL Foundation program, and Stage 2-at least 3 months after completion of the 104-hour program (Stage 2). The 3-month requirement was necessary because some Stage 2 student feedback data were captured as early as one semester after Stage 1 data, a result of the timing of the regular survey and the time that the new staff commenced teaching. As this short interval may not fully capture change, it was decided to only take into consideration those cases where Stage 2 data was captured at least 3 months after completion of the whole program.

\subsection{Data analysis}

Quantitative data were analyzed using PASW Statistics 18 . Where comparisons were necessary to identify pre- and post-program differences, related samples t-tests with alpha level of .05 were conducted. Qualitative data were analyzed using a priori coding frameworks guided by the outcomes of the program. To ensure the validity of the results, the results were triangulated from the multiple data sources, and qualitative data analysis always involved two coders to eliminate personal biases; where there were conflicts, these were negotiated through discussion. Overall, the aim of the analyses was to draw meaningful and accurate conclusions from all of the data. 


\section{Results}

\subsection{Staff's reaction (satisfaction) to the program}

Participants' reactions to the PBL Foundation program were gathered by examining their selection of training activities that they found most and least helpful to their classroom practice. They were also requested to indicate reasons why they found the selected workshop(s) most and least helpful to their facilitation. The three most commonly selected training activities that participants found most helpful was the observation of a peer coach's class (59\%), followed by the PBL Introduction workshop (51\%), and being observed in class by a peer coach with discussions (31\%). Workshops which were perceived to be less helpful were Managing the PBL classroom (15.4\%) and Encouraging meaningful reflection (12.8\%).

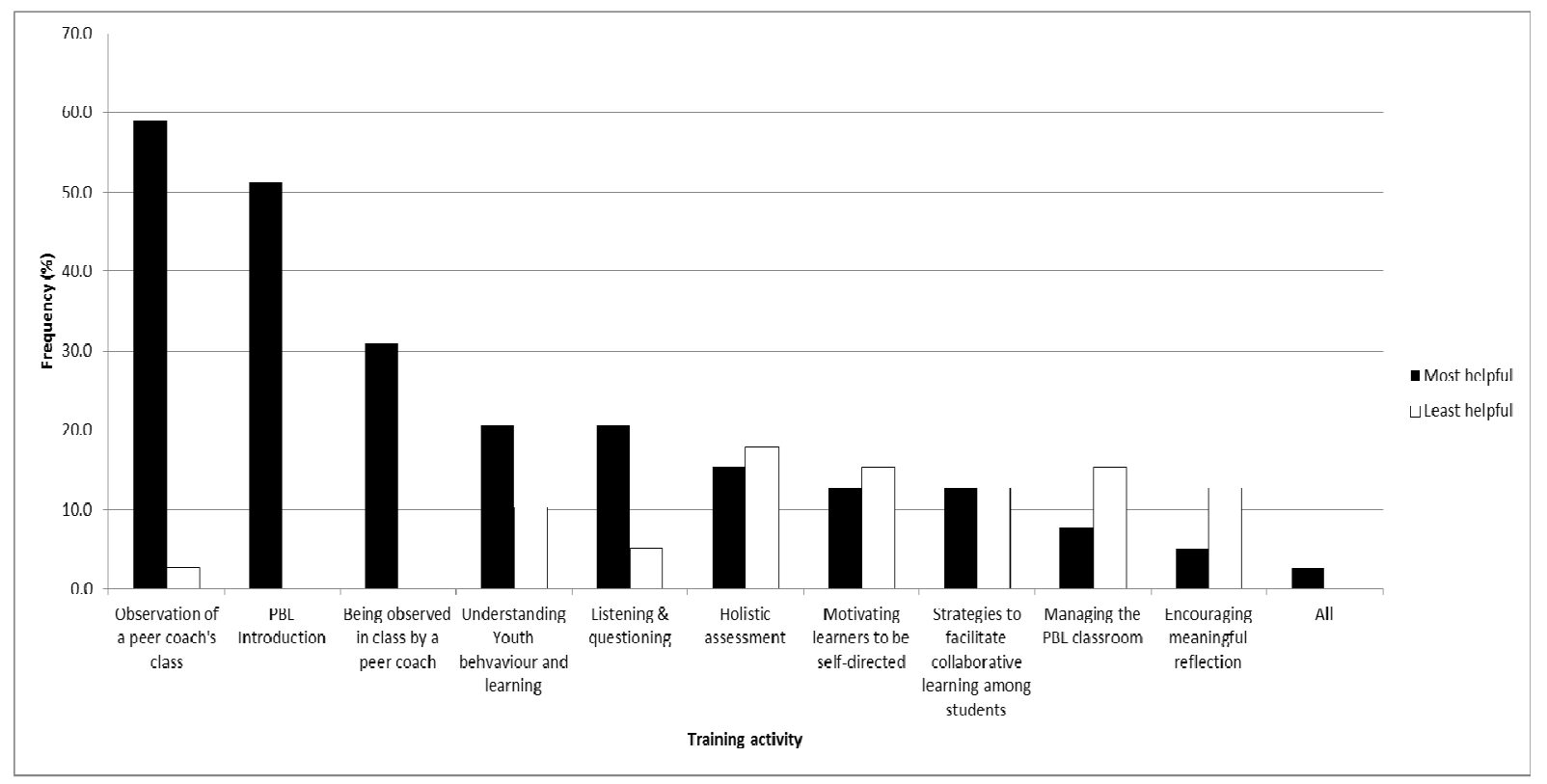

Figure 1. Frequency of most and least helpful training activities in the 104-hour PBL Foundation program.

The top three most helpful training activities were appreciated for different reasons. While the Introductory program was helpful for staff to gain an overview of PBL and to prepare them to teach using this pedagogy, peer coaching (observed and being observed) gave new staff the opportunity to observe actual facilitation in the classroom and to learn from more experienced peers, to obtain feedback on specific areas of improvement, and build confidence. In contrast to this, the continuing formal classroom-based workshops seemed to garner more varied opinion on their perceived usefulness, as shown in Figure 1. For workshops which were perceived as less helpful, participants preferred gaining knowledge by having more facilitation experience or from observing fellow colleagues; for example, one participant noted that being able to encourage meaningful reflection was something that he "could learn after some facilitation experience". Participants also suggested that the workshops could include more concrete strategies and broader application to various modules and student characteristics. Finally, there were also comments that the content of a few workshops was similar; for example, participants remarked that the workshop on Managing the PBL classroom had some overlap in content with Motivating students to be self-directed learners and Facilitative collaborative learning.

\subsection{Effect on staff's knowledge, attitudes, and beliefs}

To examine the knowledge gains of participants in the program, qualitative data in response to the survey question "What are five key ideas that you have learned from the program as a whole?" were analysed 
according to a coding scheme based on the four expected outcomes of the program; this deductive approach was taken in order to evaluate the extent to which the program was meeting its objectives. These four themes and their subthemes are:

A. Key student learning behaviors:
a. collaboration - articulating or implementing principles of collaboration in facilitation;
b. self-direction - articulating or implementing principles of self-direction in facilitation;
c. reflection - articulating or implementing principles of students' reflective learning in facilitation;

B. Understand and respond appropriately to students according to their needs - articulating or implementing principles of learner characteristics in learning;

C. Assess students holistically — articulating or implementing principles of holistic assessment in PBL;

D. Engage in meaningful reflection for professional development - recognizing the importance of reflection with self or others to improve facilitation practices.

During the process of coding, four new categories were also identified:

A. Understanding PBL - Understanding the principles underlying the pedagogy of PBL employed in the institution;

B. How to facilitate (general) - no specific facilitation strategies mentioned, just principles or broad ideas;

C. Non-facilitation related - new knowledge not related to classroom facilitation;

D. Unclassified - Blank or no meaningful response given.

Responses from each participant were coded independently by two raters, using the coding frame above. Inter-rater reliability was an acceptable $75 \%$; where there was disagreement, the two raters met together to negotiate an agreed category.

The analysis found that almost all the participants who completed the program had gained new knowledge about the key student learning behaviors, particularly with regard to principles and/or strategies for students' self-directed learning (See Table 2). A significant number had also taken away an understanding of their students and how to respond to them appropriately, followed by what it means to assess students holistically. Other frequently mentioned learning outcomes of the program include a better understanding of problem-based learning, and some general facilitation strategies.

The above analysis reflects mainly that respondents had mentioned these themes in their comments. However, as the reasoning behind the responses was less obvious, it is difficult to draw conclusions about the extent to which all the program participants had personally internalized these ideas.

Participants' attitudes and beliefs were examined via the TPI data provided by participants, as well as on their perception of confidence in five aspects of the general facilitation activities. Out of 39 participants who completed the post-program survey, 20 participants included their pre- and post-program TPI scores. The t-test revealed that participants' Developmental scores were significantly higher at the end of the 104-hour program, $t$ $=2.85 ; p=.01$ (see Table 3 ). No other differences were significant. 
Preparing staff for problem-based learning: Outcomes of a comprehensive faculty development program

Table 2

Frequency of themes and subthemes for participants' learning

\begin{tabular}{|c|c|c|c|c|}
\hline Theme & Subtheme & Example & $\begin{array}{l}\text { Frequency } \\
\text { Number of } \\
\text { participants }\end{array}$ & $\%$ \\
\hline \multirow{4}{*}{$\begin{array}{l}\text { 1. Key student learning } \\
\text { behaviors }\end{array}$} & & & 26 & 86.7 \\
\hline & Collaboration & $\begin{array}{l}\text { "Strategies to encourage discussion } \\
\text { within the team through activities such as } \\
\text { speed writing, etc." }\end{array}$ & 9 & \\
\hline & Self-direction & $\begin{array}{l}\text { "The goal is not to feed students with the } \\
\text { answers, but guiding them in becoming } \\
\text { self-directed in their learning by good } \\
\text { listening and questioning skills.". }\end{array}$ & 13 & \\
\hline & Reflection & $\begin{array}{l}\text { "ways to encourage meaningful } \\
\text { reflections" }\end{array}$ & 4 & \\
\hline $\begin{array}{l}\text { 2. Understand and } \\
\text { respond appropriately } \\
\text { to students }\end{array}$ & & $\begin{array}{l}\text { "Understanding them much better so as } \\
\text { to better reach out to them" }\end{array}$ & 12 & 40.0 \\
\hline $\begin{array}{l}\text { 3. Assess students } \\
\text { holistically }\end{array}$ & & "holistic evaluation of students" & 11 & 36.7 \\
\hline $\begin{array}{l}\text { 4. Engage in meaningful } \\
\text { reflection }\end{array}$ & & $\begin{array}{l}\text { "Facilitators are fragment of mirrors } \\
\text { reflecting learning, we should also reflect } \\
\text { on our practice only then we will become } \\
\text { better and better." }\end{array}$ & 4 & 13.3 \\
\hline 5. Understanding PBL & & $\begin{array}{l}\text { "How the PBL facilitation approach } \\
\text { forces the students to think deeper and } \\
\text { learn even better, as compared to the } \\
\text { conventional instructional teaching } \\
\text { approach." }\end{array}$ & 11 & 36.7 \\
\hline $\begin{array}{l}\text { 6. How to facilitate } \\
\text { (general) }\end{array}$ & & $\begin{array}{l}\text { "various methods to be used in } \\
\text { conducting a class" }\end{array}$ & 7 & 23.3 \\
\hline $\begin{array}{l}\text { 7. Non-facilitation } \\
\text { related }\end{array}$ & & $\begin{array}{l}\text { "Alignment of the bigger objectives of } \\
\text { what RP's wants to position in } \\
\text { education" }\end{array}$ & 1 & 3.33 \\
\hline 8. Unclassified & & "Too broad a question to answer" & 2 & 6.67 \\
\hline
\end{tabular}

Table 3

Pre- and post-program self-report scores for the Teaching Perspectives Inventory $(n=20)$

\begin{tabular}{llll}
\hline Subscale & Means & \multicolumn{1}{l}{} & \\
& Pre & Post & \\
\hline Transmission & $33.05(3.15)$ & $33.7(3.33)$ & 1.006 \\
Apprenticeship & $37.2(4.02)$ & $37.2(4.26)$ & -.062 \\
Developmental & $32.7(4.07)$ & $35.0(3.97)$ & $2.85^{*}$ \\
Nurturing & $36.9(3.72)$ & $37.1(4.82)$ & .29 \\
Social reform & $31.1(3.02)$ & $31.3(4.88)$ & .29 \\
\hline
\end{tabular}

Effect of the program on staffs' perception of confidence was examined by analyzing responses to five statements relating to their facilitation. These were based on a 4-point Likert scale ranging from Strongly Agree to Strongly Disagree (see Table 4). Overall, the mean confidence across all items was $3.22(S D=.32)$, indicating that participants agreed that the program has enabled them to conduct these five areas of facilitation. Based on 34 usable responses to this section, participants expressed the most confidence in their ability to help students to learn, followed by ability to provide the appropriate support for their students' learning, managing students in the classroom, being able to conduct the daily assessment, and gauging how well students were learning in the daily lessons. 
Lim, L.-A. Y. L. \& Choy, L. F. J.

\section{Table 4}

Confidence ratings on five areas of facilitation after the program $(n=34)$

\begin{tabular}{lllllll}
\hline \multicolumn{1}{c}{ Confidence Level } & $\begin{array}{c}\text { Strongly } \\
\text { Agree }(\%)\end{array}$ & $\begin{array}{c}\text { Agree } \\
(\%)\end{array}$ & $\begin{array}{c}\text { Disagree } \\
(\%)\end{array}$ & $\begin{array}{c}\text { Strongly } \\
\text { Disagree } \\
(\%)\end{array}$ & $\begin{array}{c}\text { Mean } \\
\text { ratings }\end{array}$ & $\begin{array}{c}\text { SD } \\
\text { Helping students to learn }\end{array}$ \\
$\begin{array}{l}\text { Ability to provide the appropriate support } \\
\text { my students need in their learning }\end{array}$ & 64.7 & 35.3 & 0 & 0 & 3.35 & .49 \\
Managing students in the classroom & 26.5 & 35.3 & 0 & 0 & 3.35 & .49 \\
$\begin{array}{l}\text { Conducting the daily assessment } \\
\begin{array}{l}\text { Ability to effectively gauge how well } \\
\text { students are learning in the daily lessons }\end{array}\end{array}$ & 17.6 & 70.6 & 1 & 2.9 & 3.24 & .50 \\
\hline
\end{tabular}

\subsection{Effect on behavior}

To explore the impact of the program on tutor behavior, student feedback data available for 30 participants' were measured at two points-once at the start of their teaching career and again after they had completed the 104 hours. There was a significant difference in the scores for two of the tutor characteristics. Use of subject-matter expertise was higher after the PBL Foundation program $(M=4.49, S D=.21)$ compared with before $(M=4.38, S D=.29), t(29)=2.44, \mathrm{p}=.02$; cognitive congruence was also higher after the program $(M=$ $3.98, S D=.25)$ as compared with before $(M=3.87, S D=.27), t(29)=2.41, p=.02$.

To further understand the behavioral impact of the program on staff's facilitation ability, participants were asked how they had applied their learning to their classroom facilitation: "Have you implemented any of the strategies you have learned in the workshops? If so, please specify". There were 31 responses to this question. Once again the qualitative data were analysed according to a coding scheme based on the four expected outcomes of the program, in order to explore its outcomes; these findings are summarised in Table 5. The analysis found that for more than half of the participants, the program had made an impact on their facilitation practices in terms of the key student learning behaviors, specifically in enabling them to incorporate more collaborative learning strategies, listening and/or questioning, and encouraging students to participate in class in their facilitation.

Fewer respondents-less than a fifth of the sample-expressed ideas related to the outcome of holistic assessment. Where these were mentioned, the idea was usually expressed very generally, e.g., "Consider holistic performance in grading", "Holistic grading"; or in terms of recognizing the need to collect information from different sources to inform the assessment of a student, e.g., "Consider the various elements of students' activity and learning in order to provide a holistic assessment".

\subsection{Internal/external factors impacting the effectiveness of the program}

To understand possible factors affecting participants' ability to apply what they had learned from the program, the survey asked "What were some barriers, if any, that prevented you from implementing what you had learned from the whole program?" A total of 27 participants gave their responses to this question. Open coding was employed to identify general themes arising from the responses.

While slightly fewer than $30 \%$ of respondents indicated that they did not perceive any barriers, at least half the sample felt that student factors presented a significant challenge to the application of their learning. Notably, participants felt that they (tutors) were unable to carry out the facilitation strategies as recommended, because their students were lacking in motivation or self-esteem, for example:

"The students' mentality of expecting to be spoon-fed with notes and resources. It can be really difficult for them to be self-directed and seek out resources on their own." 
Preparing staff for problem-based learning: Outcomes of a comprehensive faculty development program

Table 5

Frequency of themes and subthemes for behavioral impact of program

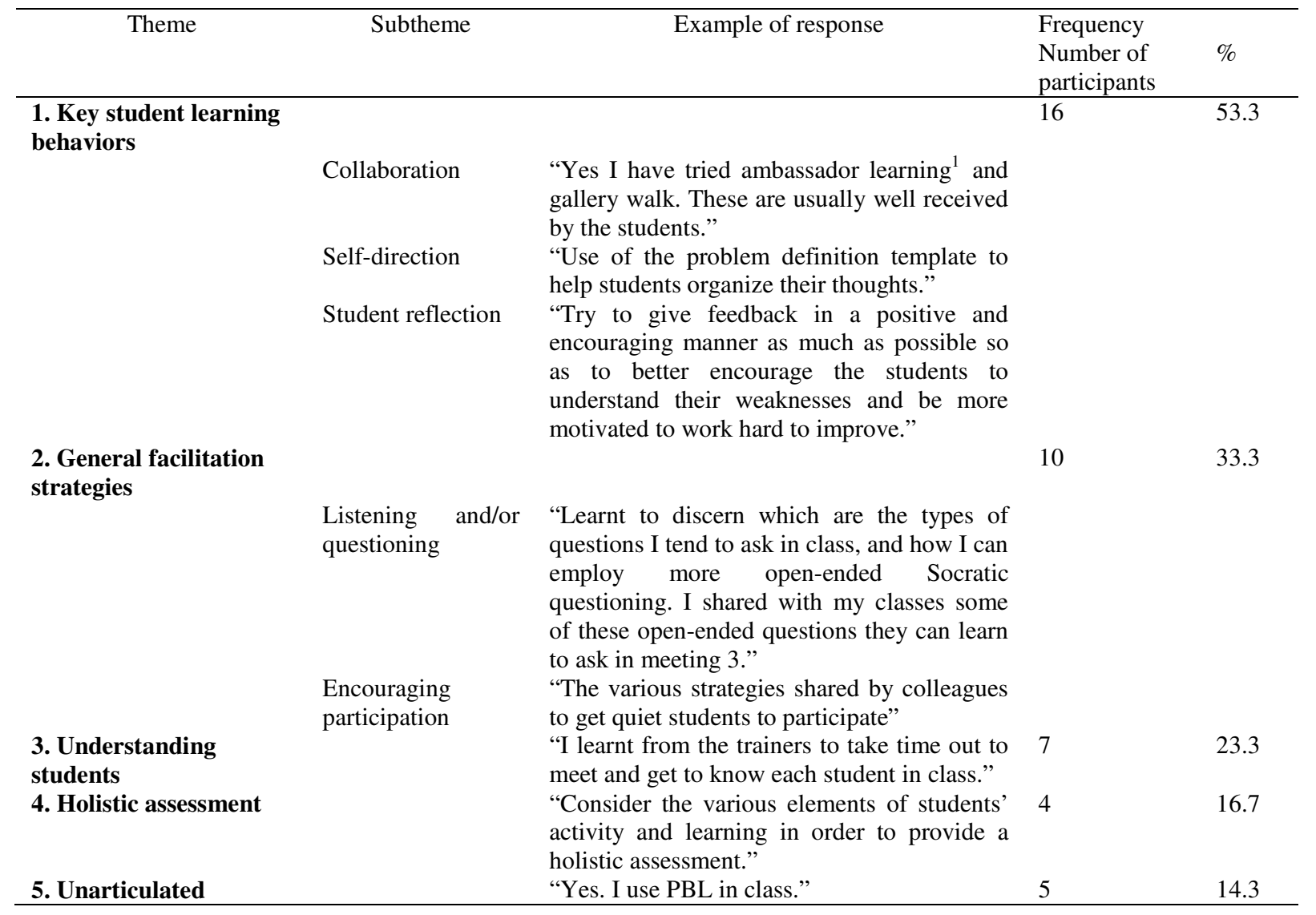

Subject content was the next frequently mentioned barrier to application of learning. In this respect, some participants felt that the nature of the subject presented a real challenge to facilitation, possibly because of the perception that students are not able to reach a revelation by themselves through facilitation. Hence, the tutor feels that it is necessary to step in to teach students the relevant concepts:

"As I'm facilitating IT subjects, sometimes prompting and not giving students direct answers could be difficult. So, at times, I need to "teach" some key IT concepts. And then, only are able to challenge them for deeper thinking."

Overall, contextual factors in the classroom were perceived to be a major source of in implementing staff's learning, in particular as these are themselves challenges for the students to be engaged in self-directed learning.

\section{Conclusion and implications}

This study aimed to describe and explore the outcomes of a structured staff development program to prepare and support new staff for PBL in a multi-disciplinary setting. The results of quantitative and qualitative analysis suggest that this structured PBL Foundation program has resulted in positive outcomes in terms of staff's reaction, learning, and behavior. It is also suggested that the program has been somewhat effective in meeting its objective in supporting new staff to acquire the knowledge, skills, competencies and attitudes required of a tutor in a problem based learning environment, and at the same time, this evaluation has also identified learning and implementation gaps which need to be addressed.

\footnotetext{
1 This is a form of collaborative learning whereby a student representative from one team visits another team, in order to share points of discussion from the representative's team.
} 
At the basic level of staff reaction, it was observed that new staff appreciated most the induction workshop to PBL as well as on-the-job training in the form of peer coaching. The significance of peer coaching in this setting highlights the point made by Guskey and Yoon (2009), that an important component of any teacher development program is follow-up- "just-in-time, job-embedded assistance as [educators] struggle to adapt new curricula and new instructional practices to their unique classroom contexts" (p. 497). The idea of peer coaching for teachers was developed by Beverly Showers and Bruce Joyce more than three decades ago, specifically to address the issue that teachers were not implementing what they had learned during training (Showers \& Joyce, 1996). Thus far, to our knowledge, in the description of professional development for problem based learning, there is little mention of a peer-coaching framework as part of tutor training. Given its importance in teacher training, and the fact that PBL can be a challenging new environment especially for novice educators, peer coaching should perhaps be a mainstay for tutor preparation for PBL. At this institution, department heads are asked to nominate staff members who have been identified as good facilitators, to take on the role of peer coaches for new staff. These nominated staff members are required to attend a one-day peer coaching workshop to help them understand the rationale of peer coaching as well as their roles as peer coach. They then work with and mentor new staff to which they are assigned, by observing their classes, and allowing them to observe their own classes. Lesson observations are guided by a structured observation sheet, and are discussed after the lesson.

At the level of staff learning, the analyses captured outcomes in terms of knowledge gains and attitudinal change. Foremost, participants recorded a higher orientation toward the Developmental perspective of the TPI after the program. The Developmental perspective has the guiding philosophy that "Effective teaching must be planned and conducted from the learner's point of view" (Pratt \& Collins, 2001). Effective Developmental teachers make the effort to examine their learners' understanding of the context from the way they think and reason about the content. Rather than being directive, a teacher, with a dominant developmental perspective, would be more inclined to facilitate through questioning and offering meaningful examples in their attempt to help learners learn. This orientation change is also reflected in staff's confidence ratings which were highest for 'Helping students to learn' and 'Ability to provide the appropriate support my students need in their learning'. Taken together, these results indicate that new staff were increasingly oriented towards helping their learners develop more complex thinking and reasoning, through effective questioning and 'bridging knowledge', which is in-line with the PBL pedagogy (Chin \& Chia, 2004). Knowledge gains reported by participants in this program are likely to have undergirded these results-participants noted that they had they had acquired a better understanding about PBL, and student learning, especially self-directed learning and collaborative learning which are the cornerstones of PBL. With such grounding in the rationale for PBL as well as what students need to do in order to take learning into their own hands, facilitators can then be more purposeful in their actions to support students in their learning.

At the level of staff behaviors, data from the student feedback survey and participants' descriptions of how they implemented their learning from the training also corroborate with the above findings. Post-program feedback indicated that staff had improved in terms of cognitive congruence and use of subject matter expertise. Earlier studies (Rotgans \& Schmidt, 2011; Schmidt \& Moust, 1995) noted that cognitive congruence is made up of both social congruence and subject-matter expertise factors due to the high variance explained by these two factors in cognitive congruence. The significant increase reported in both these characteristics after the program signifies that new staff were increasingly able to respond and reach out to students effectively with perceived higher degree of knowledge in their domain knowledge and skills. In their descriptions of implementation, participants were able to identify specifically how they had applied the key student learning behaviors in their classrooms, to bring about active learning from their students.

While this training framework had produced encouraging results for academics in the application of PBL, the evaluation was also useful to identify areas to further enhance the program. Firstly, the qualitative feedback suggested that some of the individual ongoing workshops were similar in content. This finding informed a review of the PBL Foundation program, which has since been revised. Revisions to the program involved greater streamlining of content to ensure minimal overlap across workshop offerings, as well as to equip new staff for 
Preparing staff for problem-based learning: Outcomes of a comprehensive faculty development program

their role as curriculum designers in PBL. The qualitative data also indicated that staff preferred to learn through experience-either their own or that of others-rather than through workshops, particularly where ongoing professional development was concerned. However, as this study has shown, this program has resulted in learning gains by participants. Furthermore, research by Postareff, Lindblom-Ylanne, and Nevgi (2007) has shown that experience alone is not sufficient for professional development; in particular, their study showed that when teaching experience is held constant, instructors who had attended more pedagogical training were more confident in their teaching as measured by self-efficacy. In this light, one recommendation is to help staff to identify the key takeaways from the workshops, so that they can recognize how to apply their learning. As part of the program review, e-portfolios have been incorporated into every workshop, encouraging staff to concretize their learning and more importantly, to consider specific ways that they might implement some of these ideas. Further research needs to be conducted to explore the impact of this implementation.

Secondly, the qualitative analysis found that new staff were especially concerned with being able to help students who were less motivated. This suggests that further strategies are needed to help new staff effectively engage uninterested students. It is not clear, though, from the data if this mentality is due to a gap in the Foundation training program that had not prepared tutors adequately in handling this group of students, or whether a mindset change is needed that students need guidance to be effective learners. In fact, the issue of student motivation is a real one in PBL (Savin-Baden, 2000), and Hmelo-Silver (2004) has noted that students in a PBL environment do not automatically become better learners. Academics need to see that their role as effective PBL tutors goes beyond delivering the content and executing the process. Even with good mastery of content, tutors are perceived poorly if they fail to engage students in the learning process (Dottin \& Weiner, 2001). PBL tutors have the responsibility to diagnose the situation and provide the necessary guidance to motivate uninterested students and staff development programs should prepare tutors manage this barrier.

Thirdly, although the data indicate that participants had gained knowledge about holistic assessment and a large majority (>90\%) indicated that they were confident about assessing students, their confidence rating in this aspect was slightly lower compared to other areas of facilitation. This is not surprising as studies by other researchers have reported that even the most experienced teacher finds assessment a challenge (Boud \& Feletti, 1998; Maskell, 1999). Unlike traditional forms of assessing students on their grasp of content knowledge, assessment in this pedagogy needs to be closely aligned with the goals and principles of PBL (Gijbels, Dochy, Van den Bossche, \& Segers, 2005). This means that PBL tutors are expected to execute professional judgment about the quality of students' learning, not just on the quantity (Macdonald, 2005). At this institution, for example, tutors are required to assign students with a grade based on their learning performance during the lesson. The assessment includes a holistic judgment of students' performance in three attributes: attainment of knowledge and practical skills, engagement with knowledge and practical skills, and engagement in collaborative learning. This assessment is intended to be both summative and formative-summative in that it is an indicator of how well students performed over the lesson and is included in the students' overall performance on the module; and formative in that it is accompanied by tutor feedback on how students can improve in their performance. Although it is acknowledged that the emphasis placed by different courses on the learning attributes may vary, there is an expectation that the assigned grade will represent some element of these attributes. Given these considerations, new tutors have not only to adjust to the idea of assessment in PBL, but also to grapple with understanding the idea of "professional" judgment. Given the success of peer coaching for teachers, it is suggested that, in addition to workshops, the peer coaching framework could be further adapted to develop staff's capabilities in assessing student learning. This kind of mentoring would also be helpful especially since the peer coach would be from the same department and would therefore be attuned to the differential emphases of the learning attributes.

Notwithstanding the significance of the findings above, it is acknowledged that there are limitations of this study. Foremost is the lack of a baseline measure to track development of the new staff from the time they entered the institution to the end of the program. However this was not possible due to the timing of the project, which made it impossible to find sufficient matches between the pre-program and post-program surveys. Future 
studies will involve more sustained attempts at data collection so that a big enough sample can be captured for a pre- and post- study. Secondly, apart from the student feedback measure, the data collected was based on participants' self-reports. For further research, other measures could include students' learning outcomes which may be triangulated with the results from participants' self-reports and thereby add strength to the evaluation.

The present study adds to the work of Irby (1996) and others (e.g., Murray \& Savin-Baden, 2000) in the professional development of staff in PBL; few studies have been conducted to explore the impact of such training for preparing staff to teach in this pedagogy. With this evaluation, several insights can be made with respect to tutor development. Firstly, a foundation training covering the key elements of PBL and role of the tutor is essential in helping new staff gain an understanding of PBL and their roles in facilitating students' learning before they start teaching in the classroom. This covers the aspect of knowledge attainment, procedural matters such as the tutors' role and self-awareness of their perspectives to teaching. The findings in this study indicate that knowledge is an important precursor to affecting behavioral implementation in the classroom. Secondly, a change in teaching beliefs is a pre-requisite to a change in teaching practices. To achieve this change in teaching practices, attributes such as critically reflecting on their role as a tutor in the classroom and adapting to the constructivist belief system embedded in the PBL environments on students' learning experience need to be addressed.

Successful execution of PBL is not an effortless task. To prepare and support academics' preparedness and competency in teaching in a PBL environment, a well-structured and comprehensive training program should not only provide new staff with the essential knowledge and tools to perform the job of a PBL tutor. Staff development programs also need to engage teaching staff to be reflective in their practice and support them in the continuous development to be an effective tutor. This study contributes to the literature on faculty development for PBL, and provides empirical evidence for the importance of a purposeful and sustained professional development program to prepare staff to teach with this pedagogy. In addition, the findings from this study also provide documented evidence showing the positive outcomes that are achieved with such a program. Finally, this study highlights the usefulness of having multiple sources of data and different levels of analysis, to understand the impact of a professional development program, as well as to systematically improve the rigour of the program to benefit participants.

\section{References:}

Baroffio, A., Kayser, B., Vermeulen, B., Jacquet, J., \& Vu, N. V. (1999). Improvement of tutorial skills: An effect of workshops or experience? Academic Medicine, 74(10), 75-77. http://dx.doi.org/10.1097/00001888-199910000-00045

Baroffio, A., Nendaz, M. R., Perrier, A., Layat, C., Vermeulen, B., \& Vu, N. V. (2006). Effect of teaching context and tutor workshop on tutorial skills. Medical Teacher, 28(4), 112-119. http://dx.doi.org/10.1080/01421590600726961

Boerboom, T. B. B., Dolmans, D. H. J. M., Muijtjens, A. M. M., Jaarsma, A. D. C., Beukelen, P. V., \& Scherpbier, A. J. J. A. (2009). Does a faculty development programme improve teachers' perceived competence in different teacher roles? Medical Teacher, 31(11), 1030-1031. http://dx.doi.org/10.3109/01421590903183779

Boud, D. J., \& Feletti, G. (1998). The challenge of problem-based learning: Routledge.

Chin, C., \& Chia, L. G. (2004). Problem-based learning: Using students' questions to drive knowledge construction. Science Education, 88(5), 707-727. http://dx.doi.org/10.1002/sce.10144

Clark, V. L. P., \& Creswell, J. W. (2011). Designing and conducting mixed methods research. Thousand Oaks, CA: Sage.

Collins, J. B., \& Pratt, D. D. (2011). The Teaching Perspectives Inventory at 10 Years and 100,000 Respondents Reliability and Validity of a Teacher Self-Report Inventory. Adult Education Quarterly, 61(4), 358-375. http://dx.doi.org/10.1177/0741713610392763

Dalrymple, K. R., Wong, S., Rosenblum, A., Wuenschell, C., Paine, M., \& Shuler, C. F. (2007). PBL Core Skills Faculty Development Workshop 3: Understanding PBL Process Assessment and Feedback via Scenario-Based Discussions, Observation, and Role-Play. Journal of Dental Education, 71(12), $1561-1573$. 
Preparing staff for problem-based learning: Outcomes of a comprehensive faculty development program

Dalrymple, K. R., Wuenschell, C., \& Shuler, C. F. (2006). Development and Implementation of a Comprehensive Faculty Development Program in PBL Core Skills. Journal of Dental Education, 70(9), 948-955.

Desimone, L. M. (2009). Improving Impact Studies of Teachers' Professional Development: Toward Better Conceptualizations and Measures. Educational Researcher, 38(3), 181-199. http://dx.doi.org/10.3102/0013189X08331140

Dottin, E. S., \& Weiner, M. (2001). Enhancing effective thinking and problem solving for preservice teacher education candidates and inservice professionals: Case study analysis: University Press of America.

Evans, P. A., \& Taylor, D. C. M. (1996). Staff development of tutor skills for problem-based learning. Medical education, 30(5), 365-366. http://dx.doi.org/10.1111/j.1365-2923.1996.tb00848.x

Farmer, E. A. (2004). Faculty development for problem-based learning. European Journal of Dental Education, 8(2), 59-66. http://dx.doi.org/10.1111/j.1600-0579.2003.00337.x

Gijbels, D., Dochy, F., Van den Bossche, P., \& Segers, M. (2005). Effects of problem-based learning: A meta-analysis from the angle of assessment. Review of Educational Research, 75(1), 27-61. http://dx.doi.org/10.3102/00346543075001027

Guskey, T. R. (2002). Does it make a difference? Evaluating Professional Development. Educational Leadership, 59(6), 45-51.

Guskey, T. R., \& Yoon, K. S. (2009). What works in professional development. Phi delta kappan, 90(7), 495-500.

Hmelo-Silver, C. E. (2004). Problem-based learning: What and how do students learn? Educational Psychology Review, 16(3), 235-266. http://dx.doi.org/10.1023/B:EDPR.0000034022.16470.f3

Hmelo-Silver, C. E., \& Barrows, H. S. (2006). Goals and strategies of a problem-based learning facilitator. Interdisciplinary Journal of Problem-based Learning, 1(1), 4. http://dx.doi.org/10.7771/1541-5015.1004

Hung, W. (2011). Theory to reality: A few issues in implementing problem-based learning. Educational Technology Research and Development, 59(4), 529-552. http://dx.doi.org/10.1007/s11423-011-9198-1

Hung, W., Jonassen, D. H., \& Liu, R. (2008). Problem-based learning. Handbook of research on educational communications and technology, 3, 485-506.

Irby, D. (1996). Models of faculty development for problem-based learning. Advances in Health Sciences Education, 1(1), 69-81. http://dx.doi.org/10.1007/BF00596230

Kirkpatrick, D. L. (1994). Evaluating training programs: The four levels. San Francisco: Berrett-Koehler Publishers.

Kolmos, A., Du, X.-Y., Dahms, M., \& Qvist, P. (2008). Staff development for change to problem based learning. International Journal of Engineering Education, 24(4), 772-782.

Leary, H., Walker, A., Shelton, B. E., \& Fitt, M. H. (2013). Exploring the relationships between tutor background, tutor training, and student learning: A problem-based learning meta-analysis. Interdisciplinary Journal of Problem-based Learning, 7(1), 40-66. http://dx.doi.org/10.7771/1541-5015.1331

Lekalakala-Mokgele, E. (2010). Facilitation in problem-based learning: Experiencing the locus of control. Nurse Education Today, 30(7), 638-642. http://dx.doi.org/10.1016/j.nedt.2009.12.017

Macdonald, R. (2005). Assessment strategies for enquiry and problem-based learning. In T. Barrett, I. M. Labhrainn \& H. Fallon (Eds.), Handbook of enquiry and problem-based learning: Irish case studies and international perspectives (pp. 85-93). Galway, CELT.

Maskell, D. (1999). Student-based assessment in a multi-disciplinary problem-based learning environment. Journal of Engineering Education, 88(2), 237-241. http://dx.doi.org/10.1002/j.2168-9830.1999.tb00440.x

Murray, I., \& Savin-Baden, M. (2000). Staff development in problem-based learning. Teaching in Higher Education, 5(1), 107-126. http://dx.doi.org/10.1080/135625100114993

Papinczak, T. (2010). assessment: An exploration of perceptions of tutor evaluation in problem-based learning tutorials. Medical Education, 44(9), 892-899. http://dx.doi.org/10.1111/j.1365-2923.2010.03749.x

Postareff, L., Lindblom-Ylänne, S., \& Nevgi, A. (2007). The effect of pedagogical training on teaching in higher education. Teaching and Teacher Education, 23(5), 557-571. http://dx.doi.org/10.1016/j.tate.2006.11.013

Pratt, D. D., \& Collins, J. (2001). Summaries of five teaching perspectives. Retrieved from http://teachingperspectives.com/PDF/summaries.pdf

Rotgans, J. I., \& Schmidt, H. G. (2011). The role of teachers in facilitating situational interest in an active-learning classroom. Teaching and Teacher Education, 27(1), 37-42. http://dx.doi.org/10.1016/j.tate.2010.06.025

Savin-Baden, M. (2000). Problem-based learning in higher education: Untold stories: Society for Research into 
Lim, L.-A. Y. L. \& Choy, L. F. J.

Higher Education London, England.

Schmidt, H. G., \& Moust, J. H. (1995). What makes a tutor effective? A structural-equations modeling approach to learning in problem-based curricula. Academic Medicine, 70(8), 708-714. http://dx.doi.org/10.1097/00001888-199508000-00015

Showers, B., \& Joyce, B. (1996). The evolution of peer coaching. Educational leadership, 53, 12-16.

Steinert, Y., Mann, K., Centeno, A., Dolmans, D., Spencer, J., Gelula, M., et al. (2006). A systematic review of faculty development initiatives designed to improve teaching effectiveness in medical education: BEME Guide No. 8. Medical Teacher, 28(6), 497-526. http://dx.doi.org/10.1080/01421590600902976

Stes, A., Coertjens, L., \& Petegem, P. (2010). Instructional development for teachers in higher education: Impact on teaching approach. Higher Education, 60(2), 187-204. http://dx.doi.org/10.1007/s10734-009-9294-x

Wuenschell, C. W., Dalrymple, K. R., \& Shuler, C. F. (2007). PBL core skills faculty development workshop 2: Training faculty in group learning facilitation skills through role-modeling and role-play activities. Journal of Dental Education, 71(5), 606-618. 